\title{
The Relationship between Eating Disorders and Stress among Medical Undergraduate: A Cross-Sectional Study
}

\author{
Su Wei Ngan*, Bernard Chong Khye Chern, Dhivya Dharsheni Rajarathnam, Jeevitha Balan, \\ Tan Szi Hong, Ko-Ping Tiang
}

Faculty of Medicine, Melaka Manipal Medical College (MMMC), Malaysia

Email: *suweingan@gmail.com

How to cite this paper: Ngan, S.W., Chern, B.C.K., Rajarathnam, D.D., Balan, J., Hong, T.S. and Tiang, K.-P. (2017) The Relationship between Eating Disorders and Stress among Medical Undergraduate: A Cross-Sectional Study. Open Journal of Epidemiology, 7, 85-95.

https://doi.org/10.4236/ojepi.2017.72008

Received: February 10, 2017

Accepted: April 4, 2017

Published: April 10, 2017

Copyright $\odot 2017$ by authors and Scientific Research Publishing Inc. This work is licensed under the Creative Commons Attribution International License (CC BY 4.0).

http://creativecommons.org/licenses/by/4.0/

\begin{abstract}
Introduction: Eating disorders are compulsive behaviours that can consume a person's life to the point of becoming life threatening. Medical college can be a very stressful time and previous studies had found that stress could be a main factor leading to higher risk of eating disorder. We aimed to determine the association between stress and eating disorders among undergraduate medical students. Methods: A cross-sectional study was conducted among 320 respondents comprises of Year 3, 4 and 5 medical students in private medical college in Malaysia, assessed using self-administered questionnaires which consist of social demographic data, EAT-26 and Cohen Perceived Stress Scale. The response rate of this study was $77.4 \%$. Results: With regards to EAT-26, 11.0\% of medical students were at risk of developing eating disorder and from this students who have obese BMI status (25\%) had 3.9 times more likely to develop eating disorder (95\% CI: 1.4 - 10.9). There was significant association between those with unsatisfactory social relationship with friends and peers (OR 2.5, 95\% CI 1.0 - 5.9; p value 0.035 ) and risk of developing eating disorders (OR 3.9, 95\% CI 1.4 - 10.9; p value 0.007). For Cohen Perceived Stress Scale (CPSS), $75.5 \%$ of the respondents were having high stress level. There was no significant association between stress and the risk of eating disorders with OR 1.0, 95\% CI: 0.6 - 1.7; p value 0.887 . Conclusion: Majority of medical undergraduates were under stressed and there was a risky trend toward eating disorders in medical. However, based on our results it did not portray any significant association between stress and risk of developing eating disorders. Nevertheless, it should not be completely neglected. It is important to increase the awareness of medical undergraduates regarding eating disorders and its complications.
\end{abstract}




\section{Keywords}

Eating Disorders, Stress, Medical Undergraduates, Cross-Sectional

\section{Introduction}

Eating disorders are abnormal eating habits that involve either insufficient or excessive food intake that tend to cause harm to an individual's physical and mental health. It is a psychological illness [1]. Eating disorders consist of anorexia nervosa, bulimia nervosa and binge eating disorder. Anorexia nervosa is an eating disorder that characterized by excessive weight loss, abnormal eating patterns and malnutrition. Bulimia nervosa on the other hand is compulsive over-eating followed by self-induced vomiting or laxative that is characterized by a pathological fear of gaining weight which leads to abuse eating habits and is often accompanied by guilt and depression. Binge-eating disorder is an eating disorder characterized by recurring episodes of binge eating without control mostly due to negative feelings about oneself but without any periods of compensatory behaviour such as self-induced vomiting, purging by laxatives, fasting, or prolonged exercise in between [2].

The rate of new cases of eating disorders developed had been increasing since 1950 [3]. In Malaysia, there were no concrete studies on the prevalence of eating disorders. However, it was estimated that approximately $1 \%$ of the population having anorexia nervosa and 3\% having bulimia nervosa. Anorexia nervosa usually occurs in early adolescence while bulimia nervosa happens slightly later but still within the young adult age. Hence, eating disorders are said to be common among students [4]. Eating disorders are complex conditions that involve a combination of long-standing behavioural, emotional, psychological, interpersonal, and social factors [5]. Stress is one of the major influences on the students lifestyle and eating behaviours. Stress is defined as a state of mental or emotionalstrain or tension due to constant demanding situations [6]. Studies done found that university students experience a high level of stress especially those under their undergraduate university course [6]-[13]. The major cause of stress among the undergraduate university students are difficulties of integrating into the new environment, academic workload and time management [13].

There were evidences to support that stress not only affect an individual's health through direct physiological processes but also by changing behaviours which affect health such as change in diet patterns. Some studies showed that stressed individuals have higher tendency to consume food or snacks with high calorie and high fat [14] [15], which may results in weight gain and obesity [16]. There were also worldwide scientific acceptance of the relationship between psychological stress and eating behaviours [17]. However, the findings were varied. Individuals had found to have either reduced (hypophagia) or increased food intake (hyperphagia) to overcome stress [18] [19]. Other than the amount of food, the type of food eaten was affected by psychological stress. Snack type 
foods, convenience or processed foods and sweet foods intake was found to increase among students undergoing stress; while healthy food such as vegetables tend to be neglected by the students [19] [20] [21]. Besides that, many unhealthy behaviours had been recognized to be related to high stress level such as alcohol drinking, smoking, lack of exercises, sleep disorders and bad eating habits [22]. The aim of our study was to determine the prevalence of eating disorders and association between social demographic characteristics, stress and eating disorders among undergraduate medical students in private medical institution.

\section{Methodology}

An analytical cross sectional study was done among medical undergraduate of private medical institution in Malaysia from month January to March 2016. The sample size of this study was 228 , which was estimated by using where $95 \%$ confidence level $(\mathrm{z}=1.96)$, $\mathrm{p}$ was expected prevalence of proportion and $\mathrm{d}$ was desired width of the confidence level which was $5 \%$ in this study [23]. The prevalence of the previous study shows that $18.2 \%$ of participants were at risk of eating disorders. Universal sampling was done by distributing 340 questionnaires and 263 return the questionnaires. We excluded those who were absent on that day, who did not give consent to fill up the questionnaires and incomplete questionnaires.

We approached the respondents and collected data using self-administered questionnaire with three components. The questionnaire was adapted from an authorized website for stress and eating attitude tests [24] [25]. The first component of the questionnaire was on socio-demographic data; second component was regarding the Cohen Perceived Stress Test in which it includes 10 questions regarding feelings and thoughts of the individual during the past month and the third component of the questionnaire was about Eating Attitude Test (EAT-26) in which it was a screening measure to help the individuals to determine whether they might had an eating disorder that needs professional attention. Eating Attitude Test (EAT-26) consists of 3 different parts. Part A (6 questions) which was regarding the BMI, Part B (26 questions) and Part C (5 questions) which were regarding the eating behaviour.

We graded the questionnaire separately for Cohen Perceived Stress Test and EAT-26. For Cohen Perceived Stress Test, the score was from 0 to 4 , in which 0 was given for "never" and 4 was given for "very often" except for questions number $4,5,7$ and 8 which were vice versa. A total score of 0 to 12 was considered low stress level, a total score of 13 to 20 was average stress level and lastly total score of above 20 is considered high stress level. For Part A of EAT-26, we categorize each individual based on their BMI score. BMI score of $\leq 18.5$ was considered thin, BMI score of 18.5 - 22.9 was considered normal, BMI score of 23 - 27.4 was considered as overweight and BMI score of $>27.5$ was considered as obese. Part B of Eat-26, from question 1 to question 25, a score of 3, 2, 1, 0, 0 , 0 , allocated for always, usually, often, sometimes, rarely and never respectively. For question 26, it was vice versa. A total score of 0 to $\leq 20$ is normal, if it was 21 
and above, the individual is considered to have the risk of eating disorder. For Part C of EAT-26, it was graded based on any of the checked boxes.

Cohen Perceived Stress Scale (CPSS), and Eating Attitude Test (Eat-26) which was sub-divided into 3 parts. For (CPSS) based on the score obtain, we classified the data based on 3 groups as 1) Low; <13, 2) Average; 13 - 20 and 3) High; $>20$. We used Microsoft Excel 2010 worksheet for data entry and EpiInfo ${ }^{\text {is }}$ for data analysis. We set the significance level at $\mathrm{P}<0.05$ with a confidence interval of 95\%. Descriptive statistics such as means, standard deviation, frequency and percentage was calculated. As for statistical analysis, Chi-square, Fisher exact and Odds ratio (OR) were calculated.

Approval from the Research Ethical Committee of Melaka Manipal Medical College is obtained before conducting our research. The nature of the study was explained to the students where their participation was solely voluntary and written consent was signed. The information collected was kept confidential for research purposes.

\section{Results}

A total 263 students participated in this study and response rate was $77.4 \%$. Table 1 shows socio-demographic characteristics of respondents. The mean age of the students who taken part in this study was 22.8 years (SD 1.1). 171 (65.0\%) of the students were female and $108(41.0 \%)$ of the students were Malays while 80 (34.4\%) and 63 (23.9\%) were Chinese and Indian respectively. Majority of them were single and only $1(39.1 \%)$ were staying at hostel.

Table 2 shows stress, BMI and eating disorder among students. For Cohen Perceived Stress Scale (CPSS), 109 (41.4\%) of the respondents were categorized in high stress and 136 (51.7\%) had average stress; merely 18 (6.8\%) categorized as low risk. For BMI status of the population, we categories all data into 4 different subgroup, by means 1) underweight-22 (8.3)\%; 2) Normal-151 (57.4)\%; 3) Overweight-62 (23.5)\% and 4) Obese-28 (10.6\%.) The mean value for BMI status was 22 with standard deviation of 3.8. As for EAT-26 status, $234(88.9) \%$ were categorized as "Normal", and 29 (11.0)\% in "Risky".

Table 3 shows the relationship between socio-demographic characteristics and risk of eating disorder categorized as risky and normal. There were no significant association between age, gender, race, marital status, residence, monthly allowance, student status and smoking and risk of developing eating disorder. However, students with unsatisfactory social relationship with friends and peers were significantly more likely at risk of having eating disorder (OR 2.5, 95\% CI 1.0 - 5.9; $\mathrm{p}$ value 0.035 ).

Table 4 shows the relationship between BMI, stress and risk of eating disorder. Regards to stress, there was no significant association between stress and risk of eating disorder among the students. However, students who had obese BMI status were significantly more likely to be at risk of eating disorder (OR 3.9, 95\% CI 1.4 - 10.9; $\mathrm{p}$ value 0.007). There were no significant association between underweight, overweight and risk of eating disorder. 
Table 1. Socio-demographic characteristics among students $(n=263)$.

\begin{tabular}{|c|c|}
\hline Variables & Frequency (\%) \\
\hline \multicolumn{2}{|l|}{ Age } \\
\hline $20-22$ & $87(33.0 \%)$ \\
\hline $23-25$ & $170(64.6 \%)$ \\
\hline $26-28$ & $6(2.2 \%)$ \\
\hline Mean \pm SD (Minimum-Maximum) & $22.8 \pm 1.1(20-28)$ \\
\hline \multicolumn{2}{|l|}{ Gender } \\
\hline Male & $92(34.9 \%)$ \\
\hline Female & $171(65.0 \%)$ \\
\hline \multicolumn{2}{|l|}{ Race } \\
\hline Malay & $108(41.0 \%)$ \\
\hline Chinese & $80(34.4 \%)$ \\
\hline Indian & $63(23.9 \%)$ \\
\hline Others & $12(4.5 \%)$ \\
\hline \multicolumn{2}{|l|}{ Marital status } \\
\hline Single & $204(77.5 \%)$ \\
\hline In a relationship & $58(22.0 \%)$ \\
\hline Married & $1(0.3 \%)$ \\
\hline \multicolumn{2}{|l|}{ Residency } \\
\hline Hostel & $103(39.1 \%)$ \\
\hline Non-hostel & $160(60.8 \%)$ \\
\hline \multicolumn{2}{|l|}{ Financial } \\
\hline Scholar & $147(55.8 \%)$ \\
\hline Non-scholar & $116(44.1 \%)$ \\
\hline \multicolumn{2}{|l|}{ Monthly allowance } \\
\hline$<$ RM500 & $20(7.6 \%)$ \\
\hline RM500 - RM999 & $196(74.5 \%)$ \\
\hline RM1000 - RM1499 & $35(13.3 \%)$ \\
\hline RM1500 - RM1999 & $7(2.6 \%)$ \\
\hline RM2000 - RM2499 & $4(1.5 \%)$ \\
\hline$>$ RM2500 & $1(0.3 \%)$ \\
\hline Mean \pm SD & $711.8 \pm 297.2$ \\
\hline \multicolumn{2}{|l|}{ Smoking habit } \\
\hline Yes & $12(4.5 \%)$ \\
\hline No & $251(95.4 \%)$ \\
\hline \multicolumn{2}{|c|}{ Social relationship with friends and peers } \\
\hline Satisfy & $218(82.8 \%)$ \\
\hline Not satisfy & $45(17.1 \%)$ \\
\hline
\end{tabular}


Table 2. Stress, BMI and Eating disorder among students $(n=263)$.

\begin{tabular}{cc}
\hline Variables & Frequency (\%) \\
\hline Stress (CPSS status) & \\
High & $109(41.4 \%)$ \\
Average & $136(51.7 \%)$ \\
Low & $18(6.8 \%)$ \\
BMI status & \\
Underweight & $22(8.3 \%)$ \\
Normal & $151(57.4 \%)$ \\
Overweight & $62(23.5 \%)$ \\
Obese & $28(10.6 \%)$ \\
Eating disorder (EAT-26 status) & \\
Normal & $234(88.9 \%)$ \\
Risky & $29(11.0 \%)$ \\
\hline
\end{tabular}

Table 3. The relationship between socio-demographic characteristics and risk of eating disorder.

\begin{tabular}{|c|c|c|c|c|}
\hline \multirow{2}{*}{ Variables } & \multicolumn{2}{|c|}{ Eating disorder } & \multirow{2}{*}{ OR $(95 \% \mathrm{CI})$} & \multirow{2}{*}{$P$ value } \\
\hline & Risky [N (\%)] & Normal [N (\%)] & & \\
\hline \multicolumn{5}{|l|}{ Age } \\
\hline $25-28$ & $5(55.5 \%)$ & $4(44.4 \%)$ & 1 (ref) & \\
\hline $20-24$ & $184(72.4 \%)$ & $70(27.5 \%)$ & $2.1(0.5-8.1)$ & 0.268 \\
\hline \multicolumn{5}{|l|}{ Gender } \\
\hline Male & $10(10.8 \%)$ & $82(89.1 \%)$ & 1 (ref) & \\
\hline Female & $19(11.1 \%)$ & $152(88.8 \%)$ & $1.0(0.5-2.3)$ & 0.953 \\
\hline \multicolumn{5}{|l|}{ Race } \\
\hline Chinese & $5(6.2 \%)$ & $75(93.7 \%)$ & 1 (ref) & \\
\hline Indian & $10(15.8 \%)$ & $53(84.1 \%)$ & $2.8(0.9-8.8)$ & 0.062 \\
\hline Malay & $12(11.1 \%)$ & $96(88.8 \%)$ & $1.9(0.6-5.6)$ & 0.251 \\
\hline Others & $2(16.6 \%)$ & $10(83.3 \%)$ & $3.9(0.5-17.6)$ & 0.226 \\
\hline \multicolumn{5}{|l|}{ Marital status } \\
\hline In a relationship & $41(69.4 \%)$ & $18(30.5 \%)$ & 1 (ref) & \\
\hline Single & $148(72.5 \%)$ & $56(27.4 \%)$ & $1.2(0.6-2.2)$ & 0.646 \\
\hline \multicolumn{5}{|l|}{ Residence } \\
\hline Non-hostel & $13(8.1 \%)$ & 147 (91.8\%) & 1 (ref) & \\
\hline Hostel & $16(15.5 \%)$ & 87 (84.4\%) & $2.1(1.0-4.5)$ & 0.061 \\
\hline \multicolumn{5}{|c|}{ Monthly Allowance (RM) } \\
\hline$<500$ & $14(70 \%)$ & $6(30 \%)$ & 1 (ref) & \\
\hline $500-1000$ & $139(70.9 \%)$ & $57(29.0 \%)$ & $1.0(0.4-2.9)$ & 0.931 \\
\hline$>1000$ & $(76.6 \%)$ & $11(23.4 \%)$ & $1.4(0.4-4.5)$ & 0.57 \\
\hline \multicolumn{5}{|l|}{ Student status } \\
\hline Scholar & $13(8.84 \%)$ & $134(91.16 \%)$ & 1 (ref) & \\
\hline Non scholar & $16(13.79 \%)$ & $100(86.21 \%)$ & $1.6(0.8-3.6)$ & 0.203 \\
\hline \multicolumn{5}{|l|}{ Smoking } \\
\hline No & $27(10.7 \%)$ & $224(89.2 \%)$ & 1 (ref) & \\
\hline Yes & $2(16.6 \%)$ & $10(83.3 \%)$ & $1.7(0.3-8.0)$ & 0.628 \\
\hline \multicolumn{5}{|c|}{ Realtionship with friends } \\
\hline Satisfy & $20(9.1 \%)$ & $198(90.8 \%)$ & 1 (ref) & \\
\hline Not Satisfy & $9(20 \%)$ & $36(80 \%)$ & $2.5(1.04-5.9)$ & 0.035 \\
\hline
\end{tabular}

OR: Odds ratio; 95\%CI: 95\% confidence interval; ref: reference. 
Table 4. The relationship between BMI, stress and risk of eating disorder.

\begin{tabular}{ccccc}
\hline \multirow{2}{*}{ Variables } & \multicolumn{2}{c}{ Eating disorder } & OR (95\% CI) & P value \\
\cline { 2 - 3 } & Risky [N (\%)] & Normal [N (\%)] & & \\
\hline BMI status & & & 1 (ref) & \\
Normal & $12(7.9 \%)$ & $139(92.1 \%)$ & $1.2(0.2-5.6)$ & 0.854 \\
Underweight & $2(9.1 \%)$ & $20(90.9 \%)$ & $1.7(0.7-4.4)$ & 0.260 \\
Overweight & $8(12.9 \%)$ & $54(87.1 \%)$ & $3.9(1.4-10.9)$ & 0.007 \\
Obese & $7(25 \%)$ & $21(75 \%)$ & & \\
Stress & & & $1(\mathrm{ref})$ & \\
Average and Low & $81(73.3 \%)$ & $31(27.6 \%)$ & $1.0(0.6-1.7)$ & 0.887 \\
High & $108(71.5 \%)$ & $43(28.4 \%)$ & & \\
\hline
\end{tabular}

OR: Odds ratio; 95\% CI: 95\% confidence interval; ref: reference.

\section{Discussion}

The objective of our study was to determine the prevalence of eating disorders and association between socio-demographic characteristics, stress and eating disorders among undergraduate medical students in private medical institution. A total of 109 (41.4\%) of students were in the high level stress group, where else $136(58.5 \%)$ of students were below the average group and $18(6.8 \%)$ students were in low level stress group. We found that $29(11.0 \%)$ students fall under the risky group of developing eating disorder and the remaining $234(88.9 \%)$ of students were in the normal categories that were at a low risk. In a study conducted among 435 medical students in Karachi using the same EAT-26, 22.75\% individuals were found to be at high-risk of eating disorders [26]. Another study done among university student in Bangladesh, using the EAT-26, 37.6\% of the students were classified as being at risk for an eating disorder [27].

The association between stress and the risk of eating disorders were our main concern. Among those undergraduate students, $71.5 \%$ were under high stress level and $72.3 \%$ were under average and low stress level. We found that there were no significant association between stress and the risk of eating disorders. However, a study was conducted among undergraduate students in Kuwait to see the association between stress and the risk of eating disorders. According to this study, stressed students being strongly associated with unhealthy food selection that leads to risk of eating disorders [28]. This study did not coincide with our study because there can be difference in the study load and examination pattern between our study population and their study population. There was also a study done stating that chronic stress was strongly associated to development of risk of eating disorder where $25 \%-75 \%$ of anorectic patients were found to suffer from chronic stress [29]. This can be explained by another study conducted in US to assess eating disorders among stressful medical students and showed that $15 \%$ of the female medical students had history of eating disorders [30]. 
This study depicted that there was a significant association between obesity and risk of eating disorder. According to previous studies, there was an association between obesity and binge eating which was a type of eating disorder [31]. This was also supported by another article stating that the risk of binge eating disorder increases with increasing obesity. Prevalence estimates (mostly from the USA) suggest BED affects $2 \%-5 \%$ of obese community samples [32]. In terms of social relationship with friends and peers, based on our study there was significant association with the risk of eating disorders. This is supported by a study conducted in Japan suggesting that the activity of orbito-frontal cortex which was associated with social relationship with friends and peers has significant association with the risk of eating disorders [33]. This was also supported by previous study which states that poor social relationship with friend and peers were common among eating disordered populations [34].

Other than that, there were no significant association found between other variables (social demographic factors) and risk of eating disorder in our study. However, a study in 2006 which was conducted by University of North Carolina Department of Psychiatry, showed that smoking had been reported to be used for weight control in eating disorders [35]. This did not coincide with our study, most probably due to small number students among our study population that smoked. Regarding marital status, a study was done to understand the clinical impact of marital status on the psychopathology and symptoms of eating disorder. According to this study, eating disorder patient who lives with a partner were those who presented with greater eating symptoms and psychopathology [36]. This too did not coincide with our studies as majority of our study population were single in status.

Virtually, our project contained few inevitable limitations. The participants were asked to recall the frequency of having particular feelings and thoughts like feeling upset, stressed, nervous and angry while handling the problems in the past month. Since the feelings and thoughts were very subjective manner, they may perceive of having stressed or upset "often" and "sometimes" differently. This may apparently added up into information bias gained pertaining to the study. History of alcohol consumption by the participants; which can be part of the risk factors towards this study was not asked in the questionnaire. The nature of cross-sectional study also restricts the incidence rate to be calculated and causal relationship between the variables to be interpreted in parallel.

\section{Conclusion}

It was a matter of concern to know the association between stress and risk of having eating disorder especially among medical undergraduates. However, only obesity and social insecurity portrays positive association. Nevertheless, the other variables which based on this study prove insignificant in correlation should not be completely neglected. It was an utmost importance that the students were aware of the complication of having eating disorder, since its rate of development of new cases indicates an increment since half century ago. As a 
medical institution, this was an opportunity to introduce an eating disorder education as part of the curricular syllabus to reduce this pronounced incident in the society. Lastly, the institute administration can execute a counselling session or a talk on stress management as a primary affair towards the students to reduce the stress level among them and hence can enhance the performance quality in this professional discipline. Hopefully, these suggested measures can be implemented to the society to improve the eating disorder status.

\section{Acknowledgements}

We would like to extend our utmost appreciation to all medical undergraduates for the participating in our research, and greatest gratitude to all our colleagues, Melaka Manipal Medical College, for the approval of this research. Much sincere appreciation to Associate Professor Dr. Htoo Htoo Kyaw Soe, Department of Community Medicine, Melaka Manipal Medical College for her advice and guidance on the statistical analysis and interpretation of data. We would like to thank Professor Dr. Adinegara bin Lutfi Abas, Head of Department, Department of Community Medicine, Melaka Manipal Medical College, for his steering and approval for the conduct of this study.

\section{References}

[1] Hudson, J.I., Hiripi, E., Pope Jr., H.G. and Kessler, R.C. (2007) The Prevalence and Correlates of Eating Disorders in the National Comorbidity Survey Replication. Biological Psychiatry, 61, 348-358. https://doi.org/10.1016/j.biopsych.2006.03.040

[2] National Eating Disorder Association (NEDA) (2012) Binge Eating Disorder. https://www.nationaleatingdisorders.org/binge-eating-disorder

[3] National Eating Disorder Association (NEDA) (2012) Get the Facts on Eating Disorders, New York. https://www.nationaleatingdisorders.org/get-facts-eating-disorders

[4] Mines Green Circle (2012) Eating Disorders-Anorexia Nervosa and Bulimia Nervosa. Malaysia. http://minesgreencircle.wordpress.com/2012/06/01/eating-disorders-anorexia-nerv osa-and-bulimia-nervosa/

[5] National Eating Disorder Association (NEDA) (2012) Factors That May Contribute to Eating Disorders, New York. https://www.nationaleatingdisorders.org/factors-may-contribute-eating-disorders

[6] (2014) Definition of Stress. Oxford University Press, Oxford. http://www.oxforddictionaries.com/definition/english/stress

[7] Muazzam, A. and Khalid, R. (2008) Disordered Eating Behaviors: An Overview of Asian Cultures. Journal of Pakistan Psychiatry Society (JPPS), 5, 76. http://www.pakmedinet.com/15975

[8] (2014) Eating Disorders Statistics. National Association of Anorexia Nervosa \& Associated Disorders, Naperville. http://www.anad.org/get-information/about-eating-disorders/eating-disorders-stati $\underline{\text { stics/ }}$

[9] Gan, W.Y., Nasir, M.T., Zalilah, M.S. and Hazizi, A.S. (2011) Disordered Eating Behaviors, Depression, Anxiety and Stress among Malaysian University Students. The College Student Journal, 45, 296-309. 
[10] Wong, J.G., Cheung, E.P., Chan, K.K., Ma, K.K. and Tang, S.W. (2006) Web-Based Survey of Depression, Anxiety and Stress in First-Year Tertiary Education Students in Hong Kong. Australian and New Zealand Journal of Psychiatry, 40, 777-782. https://doi.org/10.1080/j.1440-1614.2006.01883.x

[11] Stallman, H.M. (2010) Psychological Distress in University Students: A Comparison with General Population Data. Australian Psychologist, 45, 249-257. https://doi.org/10.1080/00050067.2010.482109

[12] Abdulghani, H.M., AlKanhal, A.A., Mahmoud, E.S., Ponnamperuma, G.G. and Alfaris, E.A. (2011) Stress and Its Effects on Medical Students: A Cross-Sectional Study at a College of Medicine in Saudi Arabia. Journal of Health, Population and Nutrition, 29, 516-522. https://doi.org/10.3329/jhpn.v29i5.8906

[13] Britz J and Pappas E. (2010) Sources and Outlets of Stress among University Students: Correlations between Stress and Unhealthy Habits. URJHS, 9, 1.

[14] Unusan, N. (2006) Linkage between Stress and Fruit and Vegetable Intake among University Students: An Empirical Analysis On Turkish Students. Nutrition Research, 26, 85-390. https://doi.org/10.1016/j.nutres.2006.06.002

[15] Zellner, D.A., Loaiza, S., Gonzalez, Z., Pita, J., Morales, J., et al. (2006) Food Selection Changes under Stress. Physiology \& Behavior, 87, 789-793.

[16] Laitinen, J., Ek, E. and Sovio, U. (2002) Stress-Related Eating and Drinking Behavior and Body Mass Index and Predictors of This Behavior. Preventive Medicine, 34, 29-39.

[17] Greeno, C.G. and Wing, R.R. (1994) Stress-Induced Eating. Psychological Bulletin, 115, 444-464. https://doi.org/10.1037/0033-2909.115.3.444

[18] Kandiah, J., Yake, M., Jones, J. and Meyer, M. (2006) Stress Influences Appetite and Comfort Food Preferences in College Women. Nutrition Research, 26, 118-123. https://doi.org/10.1016/j.nutres.2005.11.010

[19] Oliver, G. and Wardle, J. (1999) Perceived Effects of Stress on Food Choice. Physiology \& Behavior, 66, 511-515.

[20] Liu, C., Xie, B., Chou, C.P., Koprowski, C., Zhou, D., et al. (2007) Perceived Stress, Depression and Food Consumption Frequency in the College Students of China Seven Cities. Physiology \& Behavior, 92, 748-754. https://doi.org/10.1016/j.physbeh.2007.05.068

[21] Serlachius, A., Hamer, M. and Wardle, J. (2007) Stress and Weight Change in University Students in the United Kingdom. Physiology \& Behavior, 92, 548-553. https://doi.org/10.1016/j.physbeh.2007.04.032

[22] Al-Asadi, J.N. (2014) Perceived Stress and Eating Habits among Medical Students. International Journal of Medicine and Pharmaceutical Sciences, 4, 81-90.

[23] Lwanga, S.K. and Lemeshow, S. (1991) Sample Size Determination in Health Studies: A Practical Manual. World Health Organization, Genera, 1, 1-3. http://apps.who.int/iris/bitstream/10665/40062/1/9241544058_(p1-p22).pdf

[24] Garner, M.D. (1982) The Eating Attitude Test: Psychometric Features and Clinical Correlates. Psychological Medicine, 12, 871-878. http://www.eat-26.com/Docs/EAT-26Test-3-20-10.pdf

[25] Cohen, S., Kamarck, T. and Mermelstein, R. (1983) A Global Measure of Perceived Stress. Journal of Health and Social Behavior, 24, 386-396.

http://www.mindgarden.com/documents/PerceivedStressScale.pdf https://doi.org/10.2307/2136404

[26] (2003) Clinical Practice Guideline on Management of Obesity 2003. Ministry of Health, Malaysia. www.acadmed.org.my/view_file.cfm?fileid=183 
[27] Memon, A.A., Adil, S., Siddiqui, E.U., Naeem, S.S., Ali, S.A. and Mehmood, K. (2012) Eating Disorders in Medical Students of Karachi, Pakistan-A Cross-Sectional Study. BMC Research Notes, 5, 84.

https://www.ncbi.nlm.nih.gov/pmc/articles/PMC3395848/ https://doi.org/10.1186/1756-0500-5-84

[28] Pengpid, S., Peltzer, K. and Ahsan, G.U. (2015) Risk of Eating Disorders among University Students in Bangladesh. International Journal of Adolescent Medicine and Health, 27, 93-100. https://www.ncbi.nlm.nih.gov/pubmed/25153370

[29] Shelton, V.L. and Valkyrie, K.T. (2010) College Student Stress: A Predictor of Eating Disorder Precursor Behaviors. The Alabama Counseling Association Journal, 35, 14-23. http://files.eric.ed.gov/fulltext/EJ889697.pdf

[30] Herzog, D.B., Pepose, M., Norman, D.K. and Rigotti, N.A. (1985) Eating Disorders and Social Maladjustment in Female Medical Students. Journal of Nervous and Mental Disease, 173, 734-737. https://www.ncbi.nlm.nih.gov/pubmed/3864930 https://doi.org/10.1097/00005053-198512000-00004

[31] Mussell, M.P., Mitchell, J.E., Crosby, R.D., Seim, H.C. and Crow, S.J. (1996) Clinical Characteristics Associated with Binge Eating in Obese Females: A Descriptive Study. International Journal of Obesity and Related Metabolic Disorders, 20, 324 331. http://europepmc.org/abstract/MED/8680459

[32] Hill, A.J. (2007) Obesity and Eating Disorders. Obesity Reviews, 8, 151-155. http://onlinelibrary.wiley.com/doi/10.1111/j.1467-789X.2007.00335.x/full https://doi.org/10.1111/j.1467-789X.2007.00335.x

[33] Katayama, H., Kohmura, K., Tanaka, S., Imaeda, M., Kawano, N., Noda, Y., Nishioka, K., Ando, M., Aleksic, B., Iidaka, T. and Ozaki, N. (2014) Social Insecurity in Relation to Orbitofrontal Activity in Patients with Eating Disorders: A Near-Infrared Spectroscopy Study. BMC Psychiatry, 14, 173. http://www.biomedcentral.com/1471-244X/14/173 https://doi.org/10.1186/1471-244X-14-173

[34] Ward, A., Ramsay, R. and Treassure, J. (2000) Attachment Research in Eating Disorders. Psychology and Psychotherapy. Theory, Research and Practice, 73, 35-51. http://onlinelibrary.wiley.com/doi/10.1348/000711200160282/abstract https://doi.org/10.1348/000711200160282

[35] (2014) Futures of Palm Beach, Smoking Nictotine in Eating Disorders. http://www.futuresofpalmbeach.com/eating-disorders/nicotine/

[36] Bussolotti, D., Fernández-Aranda, F., Solano, R., Jiménez-Murcia, S., Turón, V. and Vallejo, J. (2002) Marital Status and Eating Disorders: An Analysis of Its Relevance. Journal of Psychosomatic Research, 53, 1139-1145.

www.ncbi.nlm.nih.gov/pubmed/12479997

https://doi.org/10.1016/S0022-3999(02)00336-7 
Submit or recommend next manuscript to SCIRP and we will provide best service for you:

Accepting pre-submission inquiries through Email, Facebook, LinkedIn, Twitter, etc. A wide selection of journals (inclusive of 9 subjects, more than 200 journals)

Providing 24-hour high-quality service

User-friendly online submission system

Fair and swift peer-review system

Efficient typesetting and proofreading procedure

Display of the result of downloads and visits, as well as the number of cited articles Maximum dissemination of your research work

Submit your manuscript at: http://papersubmission.scirp.org/

Or contact ojepi@scirp.org 